\title{
Air change rate effects on the airborne diseases spreading in Underground Metro wagons
}

\author{
Mostafa El-Salamony ${ }^{1} \cdot$ Ahmed Moharam $^{2} \cdot$ Amr Guaily $^{2,3,4} \cdot$ Mohammed A. Boraey ${ }^{2,4,5}$ \\ Received: 26 November 2020 / Accepted: 15 February 2021 / Published online: 22 February 2021 \\ (C) The Author(s), under exclusive licence to Springer-Verlag GmbH, DE part of Springer Nature 2021, corrected publication 2021
}

\begin{abstract}
The effect of the rate of change of fresh air inside passengers' wagons for Underground Metro on the spreading of airborne diseases like COVID-19 is investigated numerically. The study investigates two extreme scenarios for the location of the source of infection within the wagon with four different air change rates for each. The first scenario considers the source of infection at the closest point to the ventilation system while the other places the infection source at the farthest point from the wagon ventilation system. The effect of the wagon windows' status (i.e. closed or open) is also studied. It is found that under all conditions, open windows are always favored to decrease the infection spreading potential. A higher air change rate also decreases the infection spreading up to a certain value, beyond which the effect is not noticeable. The location of the infection source was found to greatly affect the infection spreading as well. The paper gives recommendations on the minimum air change rate to keep the infection spreading potentials to a minimum considering different times the passengers stay in the wagon.
\end{abstract}

Keywords COVID-19 $\cdot$ Infection potential $\cdot$ Ventilation $\cdot$ Air change rate $\cdot$ GCUM

\section{Introduction}

The Middle East and North Africa (MENA) region is one of the hottest places on earth with temperatures up to $50{ }^{\circ} \mathrm{C}$ during summer (Krarti and Ihm 2016; Hijazi and Howieson 2018). Egypt, as part of the MENA region, has an average annual cooling degree-day of about 2500 for a base temperature of $22^{\circ} \mathrm{C}$ and an average heating degree-day of about 300 for a base temperature of $18^{\circ} \mathrm{C}$ (Hijazi and Howieson 2018). This high cooling and heating load demand necessitates the

The original online version of this article was revised: The correct order of the assigned affiliations for the 3rd and 4th Author is shown in this paper.

Responsible Editor: Lotfi Aleya

Mostafa El-Salamony

elsalamony.mostafa@pku.edu.cn

Ahmed Moharam

a.moharam@phystech.edu

Amr Guaily

aguaily@nu.edu.eg

Mohammed A. Boraey

mboraey@nu.edu.eg use of ventilation equipment to ensure that the proper temperature and humidity conditions are met (Gupta et al. 2009). Metro stations are no exception to this fact with stricter constrains on the used ventilation mechanism duo to its huge impact on the Indoor Air Quality (IAQ) (Kim et al. 2012; Kwon et al. 2015; Martins et al. 2015; Qiao et al. 2015).

Egypt is one of the most populous countries in the MENA region with an estimated population of 100 million (Ahmed et al. 2020). Cairo has an estimated population of 20 million as of 2016 making it the city with the highest population in the

1 Aerospace Department, College of Engineering, Peking University, Beijing 100871, China

2 Smart Engineering Systems Research Center (SESC), Nile University, Sheikh Zayed City 12588, Egypt

3 Department of Engineering Mathematics and Physics, Faculty of Engineering, Cairo University, Giza 12613, Egypt

4 Mechanical Engineering Program, School of Engineering and Applied Sciences, Nile University, Sheikh Zayed City 12588, Egypt

5 Mechanical Power Engineering Department, Zagazig University, Zagazig 44519, Egypt 
MENA region (Ahmed et al. 2020). It is estimated that $97 \%$ of the population in Egypt are using public transportation (Ahmed et al. 2020). The reason for this high percentage is the standard of living in addition to the incentives given by the government to promote the use of more energy efficient and environmentally friendly modes of transportation (Ahmed et al. 2020).

Metro is considered as one of the most plausible modes of transportation in Greater Cairo (GC) (Awad 2002; Eldeeb et al. 2018; Eldeeb et al. 2019; Ahmed et al. 2020). The Greater Cairo Underground Metro (GCUM) is the main mode of transportation used by residents and visitors of the GC area with a capacity of up to 50,000 passengers/hour for some lines during peak hours (Eldeeb et al. 2019).

Several studies have investigated the importance of IAQ for the wellbeing of people (Ghanizadeh and Godini 2018; Guo et al. n.d.) while others considered the effect of the IAQ for metro stations on the transport of particulate matter and airborne diseases (Kim et al. 2012; Hijazi and Howieson 2018; Guo et al. n.d.; Yan et al. 2015). As recently confirmed by the World Health Organization (WHO) and several studies, COVID-19 is one of the airborne diseases which poses a great danger and high infection probability for crowded places with mechanical ventilation systems like metro stations (Correia et al. 2020).

A recent review suggests the modification of the ventilation system as a solution to mitigate the effect of the airborne pathogens by increasing the fresh air flow rate and the use of better air filters (Eldeeb et al. 2019; Wen et al. 2020).

Despite the numerous studies about the IAQ of metro stations in Egypt and other countries, the studies are limited to the stations and platforms whether underground or surface stations. An investigation about the effect of the ventilation systems and the rate of fresh air change on the spreading of airborne pathogens inside the passengers' wagons in Egypt is missing.

During the outbreak of the COVID-19 and after the lockdown measures have gradually relaxed, it is expected that many people will spend more time in ventilated public transportations or even buildings, so it is quite needed to discuss and study the flow field effects of the HVAC systems in public transportations mainly subways since it is one of the most crowded places.

Morawska et al. n.d.) proposed few ways to avoid the buildup of the viral contamination by avoiding air recirculation and increasing the ventilation rates to avoid the airborne transmission of the virus, though it discussed mainly the indoor transmission, but it was very important to study the exceptional measures to decrease the infection possibilities in the public transportation too, including subways.

Also, regarding the ventilation, the same conclusions were obtained in (Kohanski et al. 2020; Marcone 2020) where it assured the importance of introducing more flow rates in the ventilation systems in addition to extra filtration for the sources of the flow.
Chun et al. (2014) introduced a simple mathematical model to predict the number of infected people depending on few simple parameters, like number of sensitive people present in the environment, number of infected people capable of transmitting the virus, and mainly regarding the ventilation systems like the room fresh airflow rate.

In (Gupta et al. 2009), a set of equations was developed that can be used to generate boundary conditions for predicting infectious virus transport by CFD due to coughing. The work focused on the flow rate and direction and air velocity that can be determined from the human size and mouth opening area. The inputs required are height, weight, and gender of a person.

In (Zhu et al. 2006), a numerical analysis is conducted to analyze the indoor flow field assuming coughing and respiration. They assumed coughing to be a steady phenomenon, with a velocity equal to the maximum initial velocity of the coughed airflow determined by PIV experiments as the boundary condition. Then, a parametric study is conducted to analyze the transport process for droplets with diameters of $30,50,100,200,300$, and 500 micrometers using the Lagrangian equation to show how saliva droplets were expelled from the mouth by coughing, dispersed in the air, and finally attached to surfaces. Based on the results, the transport characteristics of saliva droplets produced by coughing are investigated in a calm indoor environment. The patient human model was assumed to cough consecutively, while the other human model was assumed to inhale constantly. Andrade et al. (2018) analyzed the risk of infection for practicing persons in a gymnasium considering different gyms, namely, ventilated with either split system or central system air conditioners. The study advised that ineffective ventilation increases the risk of infections such as influenza and tuberculosis. Abbasi and Samaei (2019) studied the effects of the incubation temperature on the density and composition of airborne fungi in an indoor and outdoor space of hospital. They concluded that the incubation temperature had a remarkable effect on airborne fungi.

In (Khare et al. 2015), a study on covering a cough is conducted experimentally. It is found that it can be useful in reducing the transmission of airborne infectious diseases. In order to do this, smoke is used to visualize the airflow exhaled by as much as 16 people. Their mouths were covered by several means, as cupped hands, fists, elbows, and tissues. Then that study developed simplified models for predicting the airflow based on smoke visualization data. It was found that covering a cough with a tissue, a cupped hand, or an elbow can significantly reduce the exhaled air horizontal velocity and cause the particles to move upward with the thermal plumes generated by a human body. In contrast with an uncovered cough, a covered cough or a cough with the head turned away may prevent direct exposure.

Mathematical modeling is used for the prediction of the spread of the virus whether on a global scale like national or even international scale using statistical models and also is used to predict the spread of the virus over building scales 


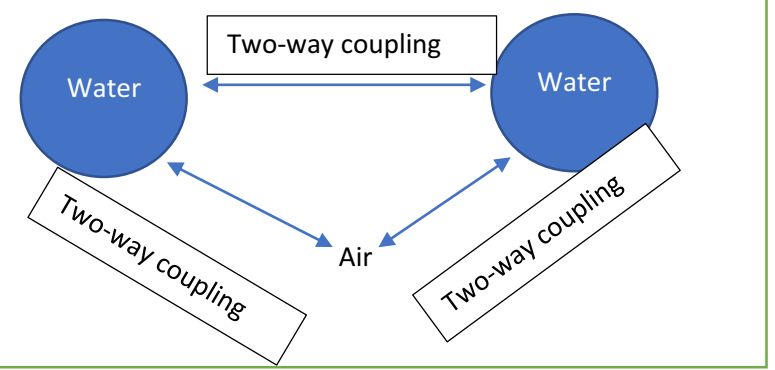

Fig. 1 Schematic for the interaction between the cough generated aerosols and the air

by tracing the path of the infection particles using differential equations. For a review on different models, see Kohanski et al. (2020).

Regarding the mathematical modeling of airborne diseases modelled as aerosols, one could think of purely Eulerian techniques (Hijazi and Howieson 2018) or mixed EulerianLagrangian techniques (Kim et al. 2012; Guo et al. n.d.) to be able to capture or track the particles causing the infection, respectively. Using OpenFOAM package, Pendar and Páscoa (2020) applied a fully coupled Eulerian-Lagrangian technique resulting in a deeper understanding of the saliva-diseasecarrier droplet transmission mechanisms. Dbouka and Drikakis (2020) used a mathematical model considering the multiphase nature of the phenomenon and considered heat transfer effects to investigate transport, dispersion, and evaporation of saliva particles and they concluded that a further work is required to quantify the influence of the environment's relative humidity (HR) and temperature. The effect of HR and the ambient wind on the value of the "physicaldistancing" is investigated using Eulerian-Lagrangian

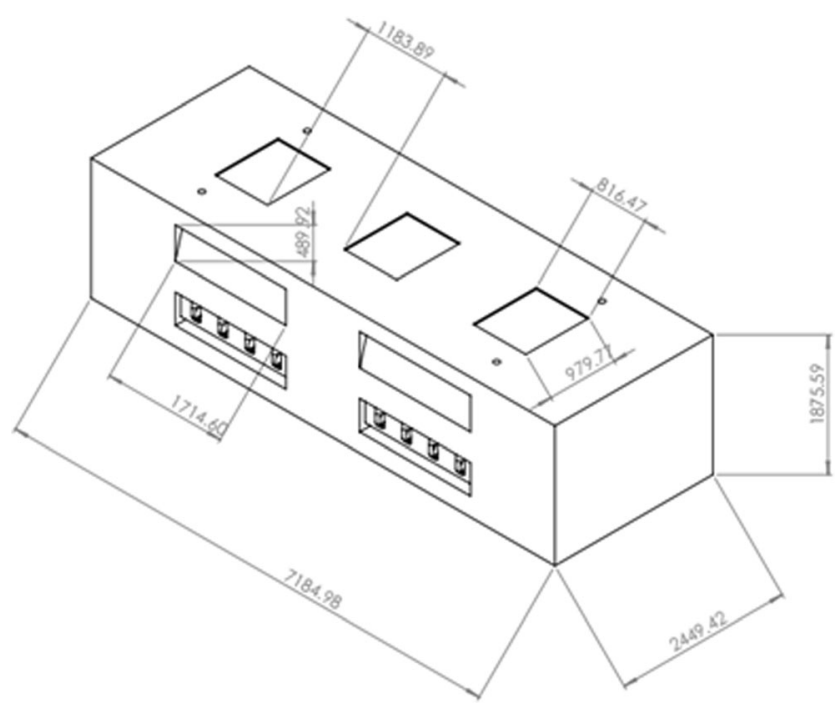

Fig. 2 Geometry of the studied wagon formulation by Feng et al. (2020) using computational fluidparticle dynamic (CFPD) simulations with the capability of predicting droplet size changes due to condensation and evaporation.

The goal of this paper is to study the transport of the coughgenerated aerosol from a patient in a metro wagon subjected to different scenarios of ventilation rates and patient position and make recommendations on the ventilation for reducing the risk of infection of COVID 19 and the similar airborne viruses.

The paper is structured as follows: in "The mathematical model", the mathematical model of the problem is stated, followed by describing the geometry, mesh, and the boundary conditions of the cases in "Problem setup". Results are discussed in "Results and discussion", and conclusions are drawn in "Summary and conclusions".

\section{The mathematical model}

The problem at hand is modeled as unsteady, compressible, turbulent, and non-isothermal ideal gas flow with dispersed incompressible constant diameter cough-generated aerosols. Fig. 1 shows a simplified schematic for the interaction between the gas and the cough-generated aerosols.

For the gas phase, the Eulerian form of the governing equations, namely, the Reynolds averaged Navier Stokes equations (RANS), for the air being modeled as non-polar compressible Newtonian fluid, are:

The continuity equation:

$\frac{\partial \rho_{a}}{\partial t}+\nabla \cdot\left(\rho_{a} \mathbf{V}_{\boldsymbol{a}}\right)=0$,

and the linear momentum equation is:

$\rho_{a}\left(\frac{\partial \mathbf{V}_{\boldsymbol{a}}}{\partial t}+\mathbf{V}_{\boldsymbol{a}} \cdot \nabla \mathbf{V}_{\boldsymbol{a}}\right)=-\nabla p+\nabla \cdot\left(\boldsymbol{\tau}_{l}+\boldsymbol{\tau}_{t}\right)+\mathbf{F}$,

while the energy equation, with no source terms, reads:

$\rho_{a} c_{v}\left(\frac{\partial T}{\partial t}+\mathbf{V}_{a} \cdot \nabla T\right)=Q+\nabla \cdot \mathbf{q}_{l}+\nabla \cdot \mathbf{q}_{t}-p t r(\mathbf{D})+\left(\boldsymbol{\tau}_{l}+\boldsymbol{\tau}_{t}\right): \mathbf{D}$,

where $\mathbf{D}$ is the rate of strain tensor defined by:

$\mathbf{D}=\frac{\mathbf{1}}{\mathbf{2}}\left[\operatorname{grad} \mathbf{V}_{\boldsymbol{a}}+\left(\operatorname{grad} \mathbf{V}_{\boldsymbol{a}}\right)^{\boldsymbol{T}}\right]$

in which the laminar extra stress tensor $\tau_{l}$ and heat flux for compressible fluids are defined by:

$\boldsymbol{\tau}_{l}=2 \mu \mathbf{D}+\lambda \operatorname{tr}(\mathbf{D}) \mathbf{I}$,

$\mathbf{q}_{l}=-h \nabla T$,

with $\lambda$ being the dilatational viscosity and is related to the 
Fig. 3 Internal wagon geometry.

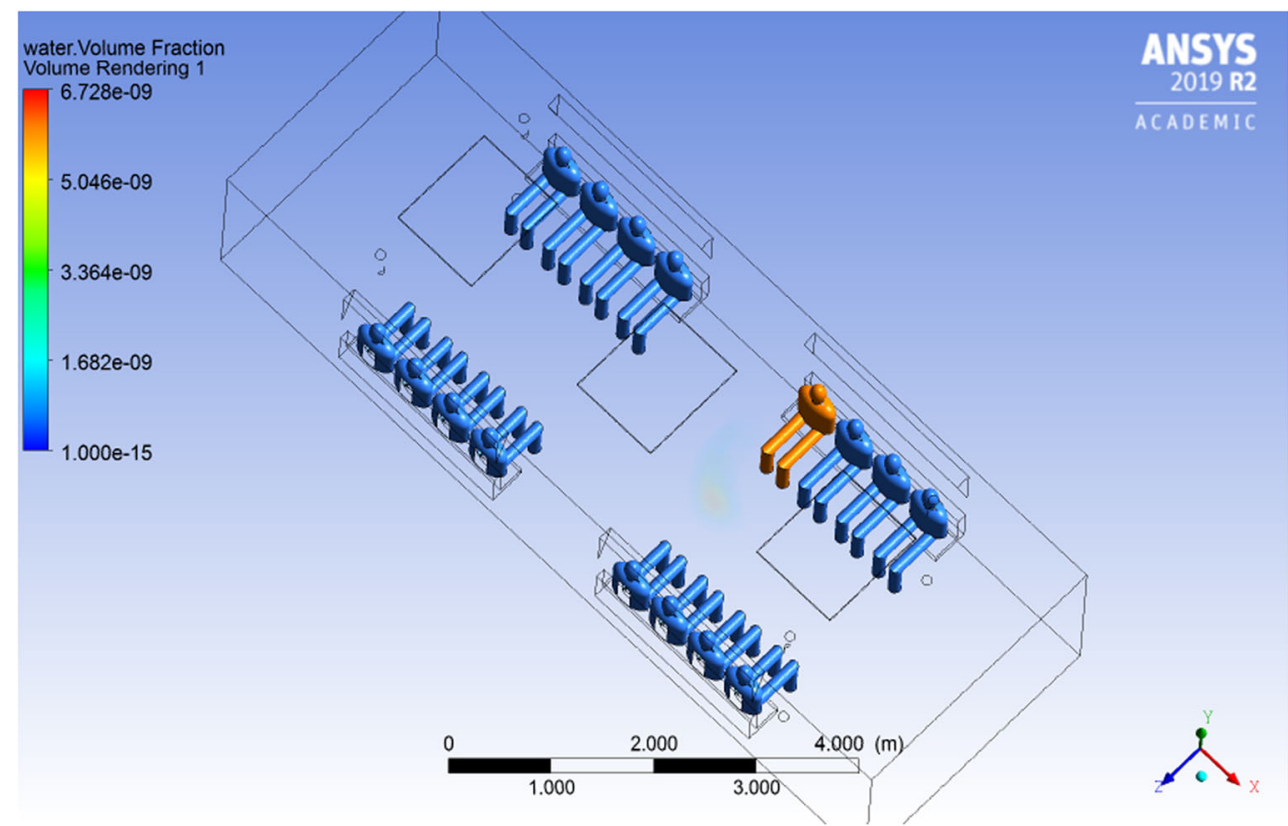

shear viscosity $\mu$ by the Stokes assumption $\lambda=-2 /{ }_{3} \mu$ and $k$ is the thermal conductivity. The dispersed cough-generated aerosols are modeled using the Lagrangian approach. For a generic water droplet, Newton's second law reads:

$$
\mathbf{F}=-\frac{\sum_{i=1}^{N} \mathbf{f}_{i}}{\sum_{i=1}^{N} V_{i}}
$$

$\frac{\mathrm{d} \mathbf{V}_{\boldsymbol{w}}}{\mathrm{d} t}=\frac{\mathbf{f}}{m}$

in which $\mathbf{f}=\mathbf{f}_{\boldsymbol{g}}+\mathbf{f}_{\boldsymbol{s}}+\mathbf{f}_{\boldsymbol{b}}$ is the total force as felt by the water droplet and $\mathbf{f}_{\boldsymbol{g}}$ is the force due to gravity, $\mathbf{f}_{\boldsymbol{s}}$ is the Stokes drag force and $\mathbf{f}_{\boldsymbol{b}}$ is the buoyancy force. The force term appearing in the momentum equation is related to the forces on the cough And the energy source term in the energy equation is:

$$
Q=-\frac{\sum_{i=1}^{N}\left(\mathbf{f}_{\boldsymbol{i}} \cdot \mathbf{V}_{w}\right)}{\sum_{i=1}^{N} V_{i}},
$$

Fig. 4 Geometry of the studied person
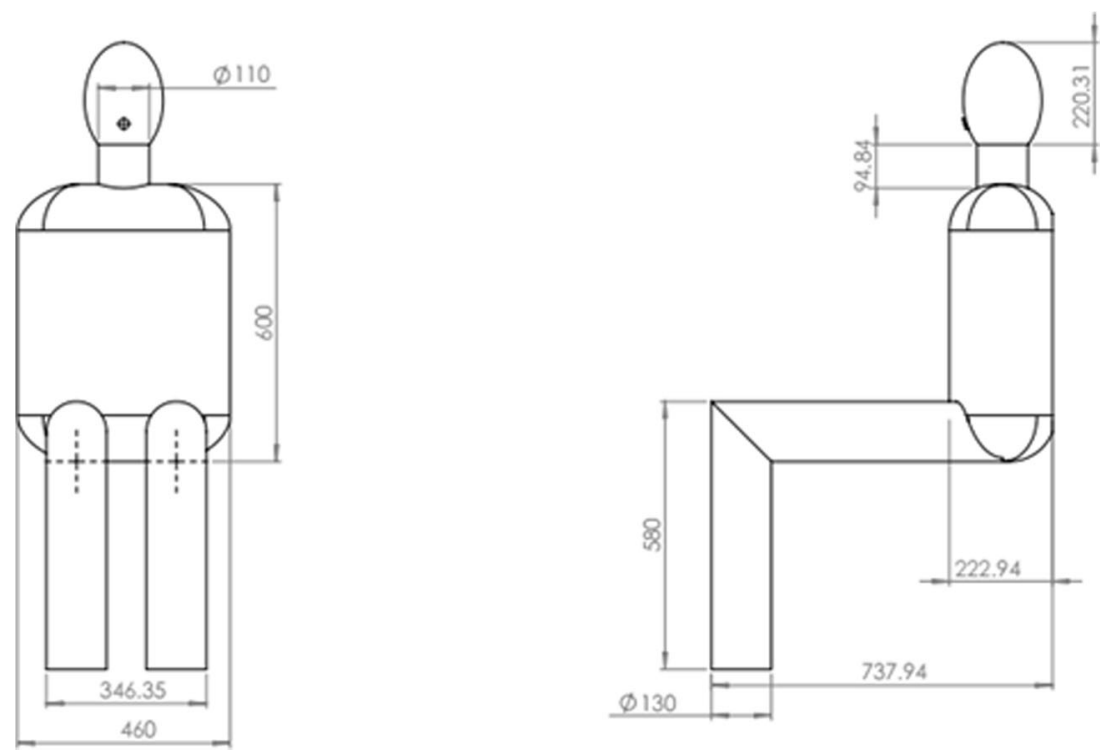
Table 1 Mesh properties

\begin{tabular}{lll}
\hline Property & Average & Standard Deviation \\
\hline Aspect ratio & 1.99 & 1.42 \\
Orthogonality & 0.73 & 0.14 \\
Skewness & 0.27 & 0.14 \\
Quality & 0.81 & 0.11 \\
\hline
\end{tabular}

Adopting the Boussinesq hypothesis for turbulence modeling, the Reynolds stress tensor for compressible flows is given by Couaillier (2000):

$\boldsymbol{\tau}_{t}=2 \mu_{t} \mathbf{D}-\frac{2}{3}\left[\rho k+\mu_{t} t r(\mathbf{D})\right] \mathbf{I}$,

and the turbulent heat flux is:

$\mathbf{q}_{t}=-h_{t} \nabla T$

With the Boussinesq hypothesis, the turbulence problem is reduced to the determination of two variables, namely, the turbulent viscosity $\mu_{t}$ and the turbulent thermal conductivity $h_{t}$ which are determined from appropriate turbulence model specifically in this work $k-\omega$ model.

The evolution equation for the turbulent kinetic energy is (Couaillier 2000):

$$
\begin{aligned}
& \rho_{a}\left(\frac{\partial k}{\partial t}+\mathbf{V}_{\boldsymbol{a}} \cdot \nabla k\right)=\boldsymbol{\tau}_{t}: \mathbf{D}+\nabla \\
& \cdot\left[\left(\mu+\mu_{t}\right) \nabla k\right]-\rho_{a} \varepsilon-R,
\end{aligned}
$$

and for the dissipation rate of $k$ is:

$\rho_{a}\left(\frac{\partial \varepsilon}{\partial t}+\mathbf{V}_{\boldsymbol{a}} \cdot \nabla \varepsilon\right)=1.57 \frac{\varepsilon}{k} \boldsymbol{\tau}_{t}: \mathbf{D}+\nabla \cdot\left[\left(\mu+\frac{\mu_{t}}{1.3}\right) \nabla \varepsilon\right]-2 c \frac{\varepsilon^{2}}{k}+E$, with

$$
\begin{aligned}
& R=2 \mu(\nabla \sqrt{k})^{2}, E=\frac{2 \mu \mu_{t}}{\rho}\left(\frac{\partial^{2} V_{t}}{\partial n^{2}}\right)^{2}, c=1-0.3 \exp \left(-R_{e t}{ }^{2}\right) \\
& , h_{t}=\frac{c_{p \mu_{t}}}{\operatorname{Pr}_{t} \text { and } R_{e t}=\frac{\rho k^{2}}{\mu \varepsilon} .} \\
& \text { The turbulent viscosity is by (Couaillier 2000): }
\end{aligned}
$$

$\mu_{t}=0.09 R_{e t} \exp \left(\frac{-2.5}{1+0.02 R_{e t}}\right)$

In the above equations, $\rho_{a}$ is the air density, $\mathbf{V}_{\boldsymbol{a}}$ is air velocity vector, $p$ is the thermodynamics pressure to be determined from the perfect gas equation of state, and $m$ is the mass of the water droplet.

\section{Problem setup}

\section{Geometry}

The geometry of the used metro wagon is illustrated in Fig. 2. The volume of the available space is $58 \mathrm{~m}^{3}$. It contains three HVAC openings, with area of $0.8 \mathrm{~m}^{2}$ each and a distance of $1.18 \mathrm{~m}$ between each other. The wagon has four windows, open with 15 degrees.

Besides, the wagon contains 4 seats, each one has three people, and so 12 people are located (one of them is considered to be infected and setting near to the central ventilation window, as illustrated in Fig. 3). Dimensions of the person's model are shown in Fig. 4.

\section{Mesh}

The meshing sizing is as follows: mesh element size over all the faces and mouths is $5 \mathrm{~mm}, 20 \mathrm{~mm}$ over the bodies, and $50 \mathrm{~mm}$ in the rest of the domain. Hence, the total number of elements is 7.8 million. The mesh is demonstrated in Figs. 5 and 6, and the mesh statistics is listed in Table 1.
Fig. 5 Side cross-section of the used mesh (n)

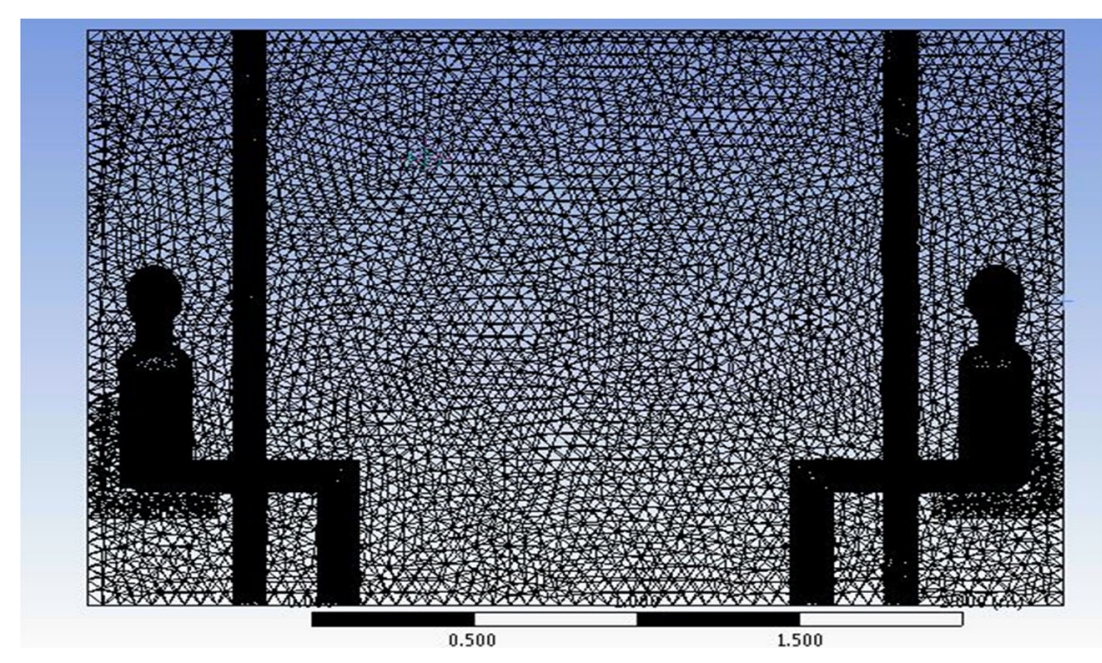




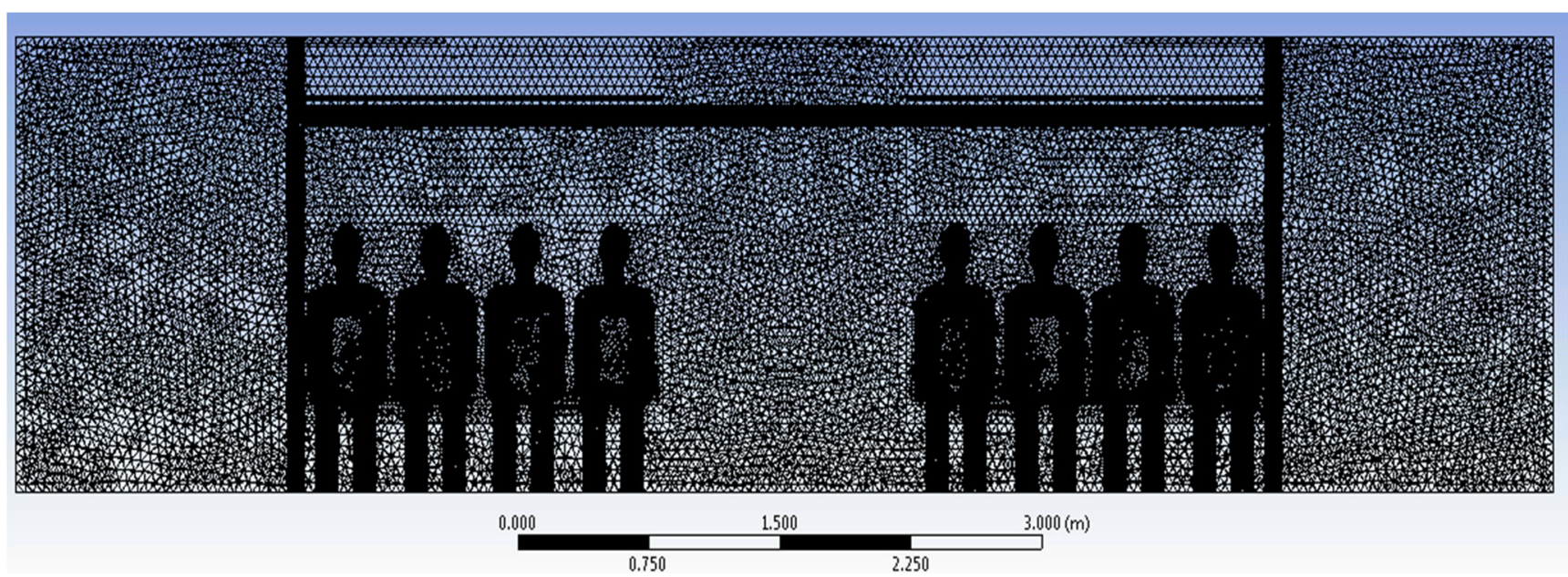

Fig. 6 Front cross-section of the used mesh

\section{Boundary conditions}

The boundary conditions for exhalation can be summarized as follows (Gupta et al. 2009; Gupta et al. 2011; Wen et al. 2020): air speed of coughing changes according to the lung size, which can be approximated to Gamma function that is described by three main parameters: Cough Peak Flow Rate (CPFR), Peak Velocity Time (PVT), and Cough Expired Volume (CEV) that is the area under the curve in Fig. 7. These parameters are correlated by the patient's length and mass, as in the equations below.

Cough Peak Flow Rate (CPFR)

$$
\begin{aligned}
\operatorname{CPFR}(l / s)= & -8.8980+6.3952 \mathrm{~h}(m) \\
& +0.0346 \mathrm{w}(\mathrm{kg}), \text { for male }
\end{aligned}
$$$$
\operatorname{CPFR}(l / s)=-3.9702+4.6265 \mathrm{~h}(m) \text {, for female }
$$

Cough Expired Volume (CEV)

$\operatorname{CEV}(l)=0.138 \operatorname{CPFR}(1 / s)+02983$, for male

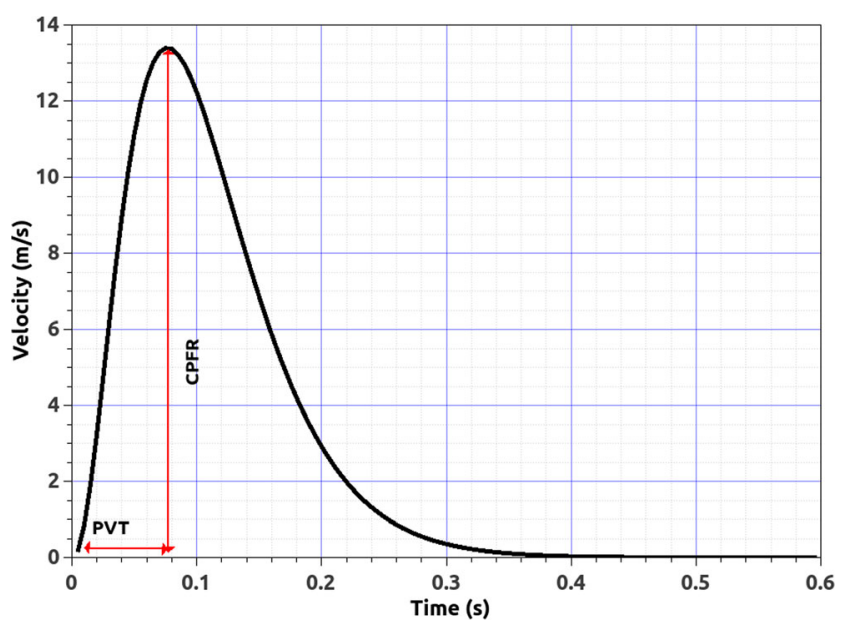

Fig. 7 Variation of coughing velocity with time
$\operatorname{CEV}(l)=0.0204 \operatorname{CPFR}(1 / s)-0.043$, for female

Peak Velocity Time (PVT)

$\operatorname{PVT}(m s)=1.360 \mathrm{CPFR}(1 / s)+65.860$, for male

$\operatorname{PVT}(m s)=3.152 \mathrm{CPFR}(1 / s)+64.631$, for female

Mouth opening area (MOA)

$\mathrm{MOA}=4 \pm 0.95 \mathrm{~cm}^{2}$, for male

$\mathrm{MOA}=3.370 \pm 1.40 \mathrm{~cm}^{2}$, for female

Size distribution and quantity of the droplets also change considerably according to the exit from the infected person. As shown in Table 2, the most critical case is coughing; hence, it is decided in this article to investigate coughing in a metro wagon.

It is assumed that all the droplets exhaled during coughing are of one size of $8.5 \mu \mathrm{m}$. Coughing velocity of the cough is presented in Fig. 7, and the respiration follows Equation 22. It is assumed that all people breathe and cough from mouth to have more realistic flow behavior; different people have different phase shifts.

$V_{\text {breath }}=4.5 \sin (\omega t+S)[\mathrm{m} / \mathrm{s}]$

where $\omega$ is the breathing frequency, $t$ is time, and $S$ is the phase shift. It is assumed that the normal breath rate is 17 per minute, and the phase shift varies to make the flow inside the wagon

Table 2 Size distribution and quantity of the droplets [ref_20]

\begin{tabular}{lll}
\hline Exhalation & Droplet Diameter $(\mu \mathrm{m})$ & Number of droplets \\
\hline Coughing & 8.5 & $10^{6}$ per cough \\
Breathing & 0.4 & 525 per breath \\
Talking & 30 & 2250 for $15 \mathrm{sec}$ of talk \\
\hline
\end{tabular}


Table 3 Boundary conditions

\begin{tabular}{lll}
\hline Boundary & Property & Value \\
\hline Bodies & Velocity & No slip \\
& Temp & Sick: 33/healthy: $32^{\circ} \mathrm{C}$ \\
\multirow{3}{*}{ Mouths } & Velocity & Equation 22, Fig. 7 \\
& Temp & Sick: 33/healthy: $31^{\circ} \mathrm{C}$ \\
Droplets & Size & $8.5 \mu \mathrm{m}$ \\
& Water volume fraction & $3.216 e-7$ \\
Seat & Velocity & No slip \\
& Temp & Adiabatic \\
HVAC & Inlet volume flow rate & $16,24,32,40 \mathrm{CFM}$ per person \\
& Inlet air temperature & $18{ }^{\circ} \mathrm{C}$ \\
& Turbulence intensity & Medium $(5 \%)$ \\
Wagon wall & Velocity & No slip \\
& Temp & 25 \\
\hline
\end{tabular}

more realistic. Temperatures of the bodies are 32 and $33{ }^{\circ} \mathrm{C}$ for the healthy and sick people, respectively.

Considering the wagon, wall temperature is $25^{\circ} \mathrm{C}$, and the walls have no-slip condition. The ventilation flow rate varies from 16 to 40 cubic feet per minute (CFM), and the temperature is $18{ }^{\circ} \mathrm{C}$. For brevity, all the boundary conditions are presented in Table 3 .

\section{Results and discussion}

In order to quantify the risk of COVID-19 propagation, a case study is simulated as follows. At time 0, one patient coughs, exhaling air-water mixture, while other people breathe normally, and the ventilation system continuously supplies fresh air. It is assumed that water is initially dispersed, and the

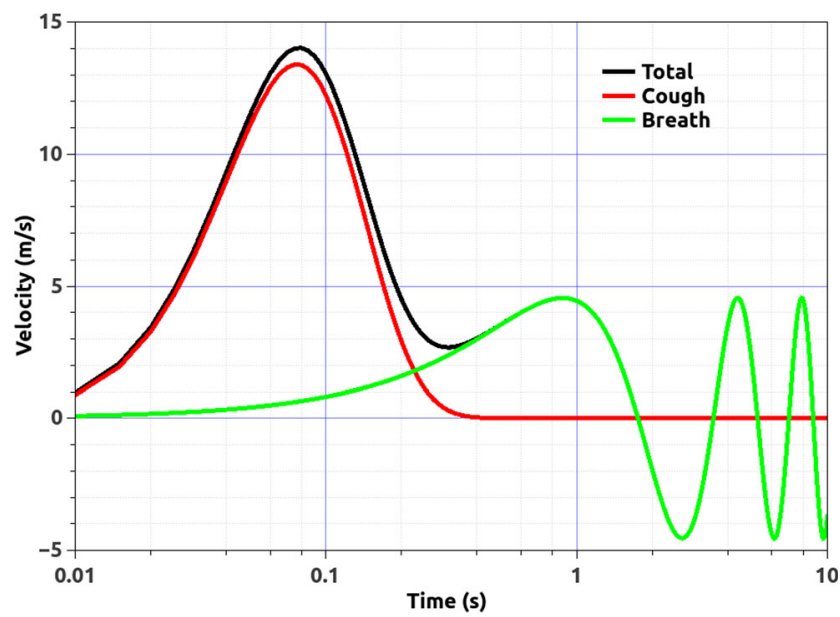

Fig. 8 Couching and breathing velocity profiles

infection is carried on these droplets. Hence, the water content in the whole metro wagon is used to identify the presence of the infection. Namely, the ratio of water volume divided by the whole volume of the wagon is measured in this study. The simulations are done using ANSYS CFX on 64 cores. The computational time for one simulation is 576 hours/core.

Three sets of numerical simulations were conducted. The first set simulates the patient to sit close to the ventilation suction window, which represents the best-case scenario, and the flow rate of the ventilation system changes from 16 to $40 \mathrm{CFM}$ per passenger, corresponding to air changes per hour $(\mathrm{ACPH})$ of 0.47 to 1.17 which were calculated using Equation (23).

$$
\mathrm{ACPH}=60 * \mathrm{CFM} / \text { volume }
$$

The second set represents the case where the patient sits away from the ventilation suction window, which represents the worst-case scenario, and the ventilation flow rate changes also. The third and fourth cases study the window's effect, by

Table 4 Investigated cases

\begin{tabular}{|c|c|c|c|c|}
\hline \multirow[t]{2}{*}{ Case number } & \multicolumn{2}{|c|}{ Volume flow rate } & \multirow[t]{2}{*}{ Window status } & \multirow[t]{2}{*}{ Patient position } \\
\hline & $\mathrm{ACPH}$ & CFM & & \\
\hline 1 & 0.47 & 16 & Closed & Close to air exit window \\
\hline 2 & 0.70 & 24 & Closed & Close to air exit window \\
\hline 3 & 0.94 & 32 & Closed & Close to air exit window \\
\hline 4 & 1.17 & 40 & Closed & Close to air exit window \\
\hline 5 & 0.47 & 16 & Closed & Close to air inlet window \\
\hline 6 & 0.70 & 24 & Closed & Close to air inlet window \\
\hline 7 & 0.94 & 32 & Closed & Close to air inlet window \\
\hline 8 & 1.17 & 40 & Closed & Close to air inlet window \\
\hline 9 & 0.47 & 16 & Open & Close to air exit window \\
\hline 10 & 0.70 & 24 & Open & Close to air exit window \\
\hline 11 & 0.47 & 16 & Open & Close to air inlet window \\
\hline
\end{tabular}


Fig. 9 Aerosol retention in the best-case scenario

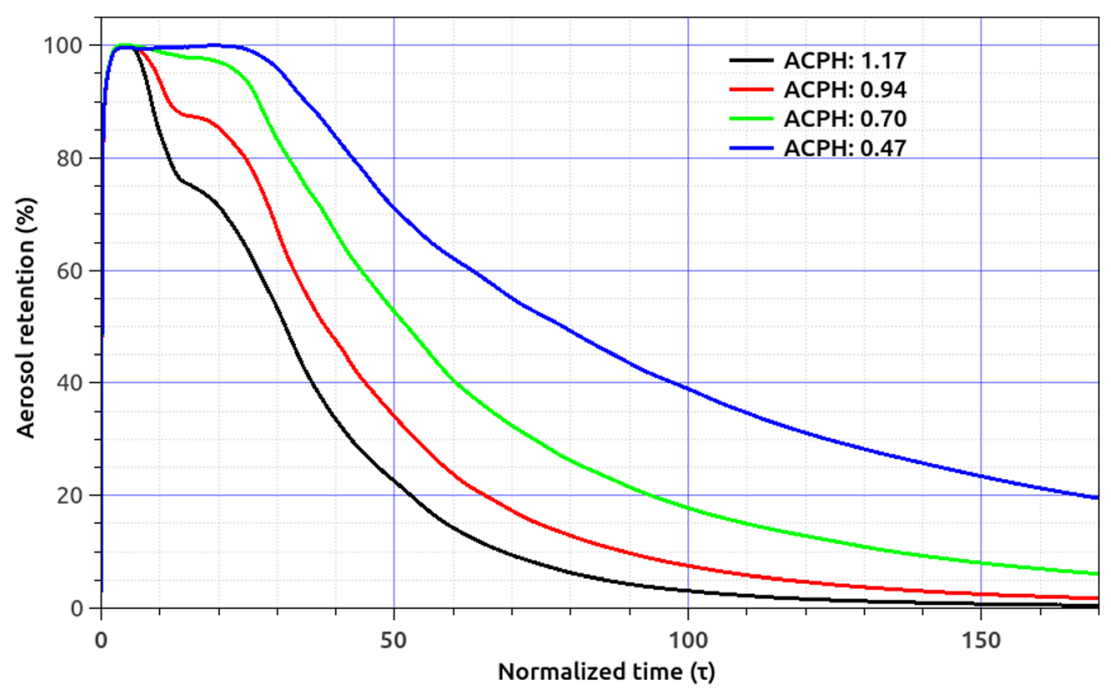

comparing cases where the wagon windows are closed with those where the windows are open, in both the best and worst cases. In these cases, the ventilation flow rate changes from 16 to 24 CFM. The simulated cases are summarized in Table 4.

\section{Best-case scenario}

In this simulation, the patient starts coughing, according to the default coughing profile shown in Fig. 8, then breathes normally, as the other passengers. While coughing, the ratio of water volume divided by the whole space volume was noted here by Water Volume Ratio (WVR), increases. Besides, the ventilation system continuously supplies fresh air to the wagon and throws out the old. Through this process, the old air and water are removed out from the wagon, and hence, the WVR decreases with time.

It can be seen from Fig. 9 that as time increases, the WVR decreases suddenly, then decays exponentially. Both sudden and exponential rates depend on the ventilation flow rate. WVR reduced to $50 \%$ of its maximum in 280 seconds for the 0.468136 ACPH case, while it takes 184 and 134 seconds for 0.702204 and $0.936271 \mathrm{ACPH}$ and 110 seconds for 1.170339 ACPH.

After 10 minutes, WVR reached $19 \%, 6 \%, 2 \%$, and $0.5 \%$ for $0.468136,0.702204,0.936271$, and 1.170339 ACPH per passenger. This shows that increasing the flow rate from 0.468136 to $0.702204 \mathrm{ACPH}$ reduces the danger of infection, while the change from 0.936271 to 1.170339 does not have a significant effect.

\section{Worst-case scenario}

In this scenario, the patient sits far from the ventilation exit; hence, cough-generated aerosols take longer time to go out, as shown in Fig. 10. In this figure, the best and worst cases, denoted by Cases I and II, are compared together, for 16
Fig. 10 Aerosol retention in the best and worst scenarios

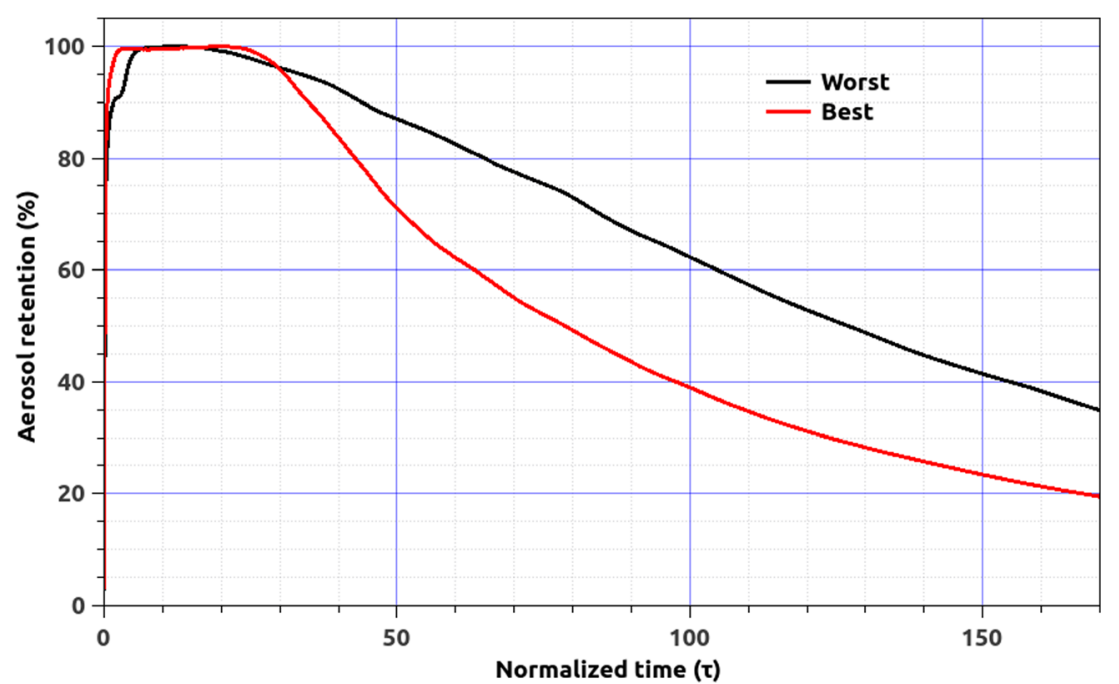


Fig. 11 Aerosol retention in the worst-case scenario

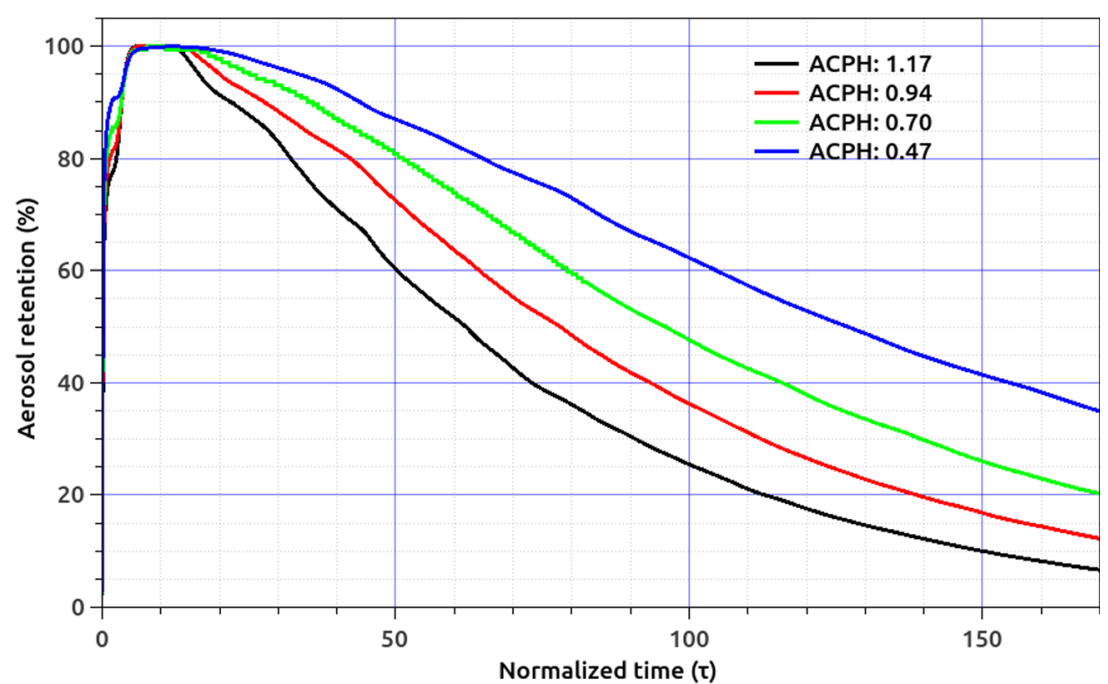

CFM. It is shown that the initial WVR rises in both cases are similar, till 100 seconds. Then Case I starts the exponential WVR reduction with higher rate compared to the other case. This make WVR reach $50 \%$ of its maximum in 444 seconds, compared to 280 seconds for Case I, i.e., $58 \%$ more time. After 10 minutes, WVR for Case II is $35 \%$ compared to $19 \%$. This indicates the large variation generated from the location of the patient with respect to the ventilation exit window.

It can be seen from Fig. 11 that as time increases, the WVR level is maintained constant then decreases exponentially. Both being-constant time and decaying rate depend on the ventilation flow rate. WVR reduced to $50 \%$ of its maximum in 451 seconds for the 16 CFM case, while it takes 339 and 276 seconds for 24 and $32 \mathrm{CFM}$ and 219 seconds for $40 \mathrm{CFM}$. After 10 minutes, WVR reached $35 \%, 20 \%, 12 \%$, and $7 \%$ for $16,24,32$, and $40 \mathrm{CFM}$ per passenger. This shows again that increasing the flow rate from 16 to $24 \mathrm{CFM}$ reduces the danger of infection, while the change from 32 to 40 does not produce a significant effect. Also, it indicates that sitting away from the ventilation exit can dramatically increase the infection probability, as the ventilation inlet air can block the circulation of the air and the cough-generated aerosols would be trapped in one region of the wagon. Another evidence for the "circulation blockage" is that for the highest flow rate the water volume reached the highest value compared to all other cases, which means that the droplets were not allowed to exit the domain because of the high flow rate that blocked the path to the exit in front of the droplets. This shall be investigated in detail in a further study.

\section{Window's effect}

As illustrated in Fig. 12, opening windows can lead to considerable reduction in WVR. Quantitatively speaking, to reach 50\% WVR, it takes 167 seconds for the 16 CFM open case,
Fig. 12 Aerosol retention in the closed and open window conditions-best-case scenario

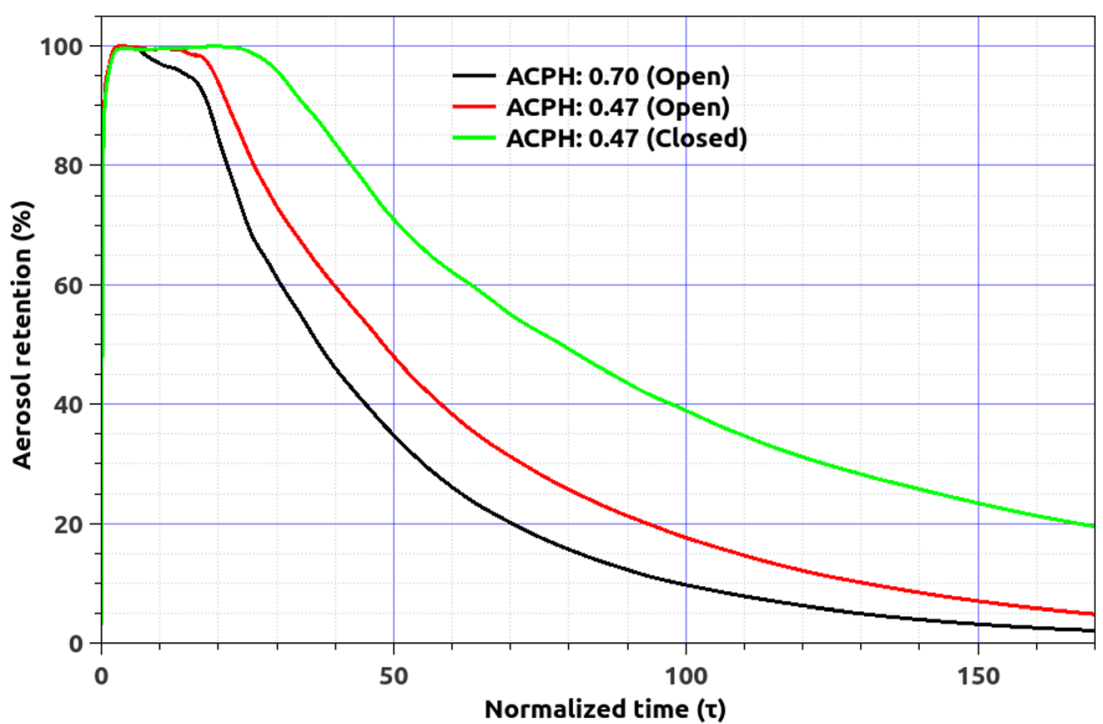


Fig. 13 Aerosol retention in the closed and open window conditions at different air flow rates - best-case scenario

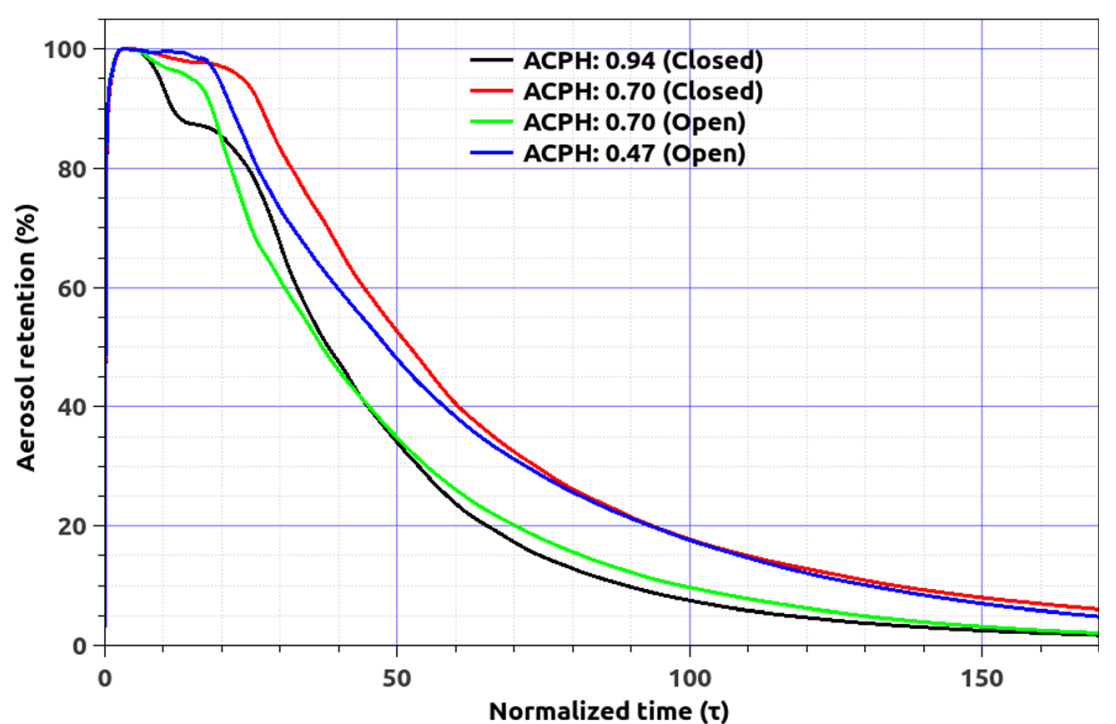

compared to 280 seconds for the closed window case, i.e., $40 \%$ less time. After 10 minutes, WVR reached 5\% compared to $19 \%$ of the closed window case. Hence, one concludes the importance of keeping the windows open to reduce the infection risk.

To have better insight of the window's effect, open window cases are compared with closed windows for different flow rates. As illustrated in Fig. 13, for 16 CFM, the open windows case is asymptotically similar to the 24 CFM the closed windows case and the same for 24 CFM open with 32 CFM closed. Hence, one concludes that opening windows can be equivalent to increasing the flow rate by 1.5 times.

Considering the worst-case scenario, Fig. 14 shows that when the windows are open and the flow rate is 16 CFM per passenger, the water content decreases dramatically even faster than the 24 CFM case. Quantitatively speaking, the $50 \%$ of water content go out after 247 seconds, compared to 451 seconds for the same flow rate and 339 for 24 CFM. After 10 minutes, WVR decreased to $35 \%$ and $20 \%$ for 16 and 24 CFM, respectively. This again confirms the conclusion that windows have an important role in mitigating the infection spread. Results of all cases are summarized in Table 5 .

The effect of pressure difference between the wagon and the ambient atmosphere can be inferred by comparing the aerosol retention between the windows-open and windows-closed cases with time for the same volume flow rate. It can be seen from the difference shown in Fig. 15 that there are slow and fast variations in the
Table 5 Results of the investigated cases

\begin{tabular}{lllllll}
\hline \multirow{2}{*}{ Case number } & \multicolumn{2}{l}{ Volume flow rate } & & \multicolumn{2}{l}{ Time to 50\% WVR } & \multirow{2}{*}{ WVR \% after 10 minutes } \\
\cline { 2 - 3 } & ACPH & CFM & & Normalized & [Second $]$ & \\
\hline 1 & 0.47 & 16 & & 79.7 & 280 & 19 \\
2 & 0.70 & 24 & & 52.4 & 184 & 6 \\
3 & 0.94 & 32 & & 38.2 & 134 & 2 \\
4 & 1.17 & 40 & & 31.3 & 110 & 0.5 \\
5 & 0.47 & 16 & & 128.4 & 451 & 35 \\
6 & 0.70 & 24 & & 96.5 & 339 & 20 \\
7 & 0.94 & 32 & & 78.6 & 276 & 12 \\
8 & 1.17 & 40 & 62.3 & 219 & 7 \\
9 & 0.47 & 16 & & 47.5 & 167 & 5 \\
10 & 0.70 & 24 & 37.0 & 130 & 2 \\
11 & 0.47 & 16 & 69.8 & 245 & 11 \\
\hline
\end{tabular}


Fig. 14 Aerosol retention in the closed and open window conditions - worst-case scenario

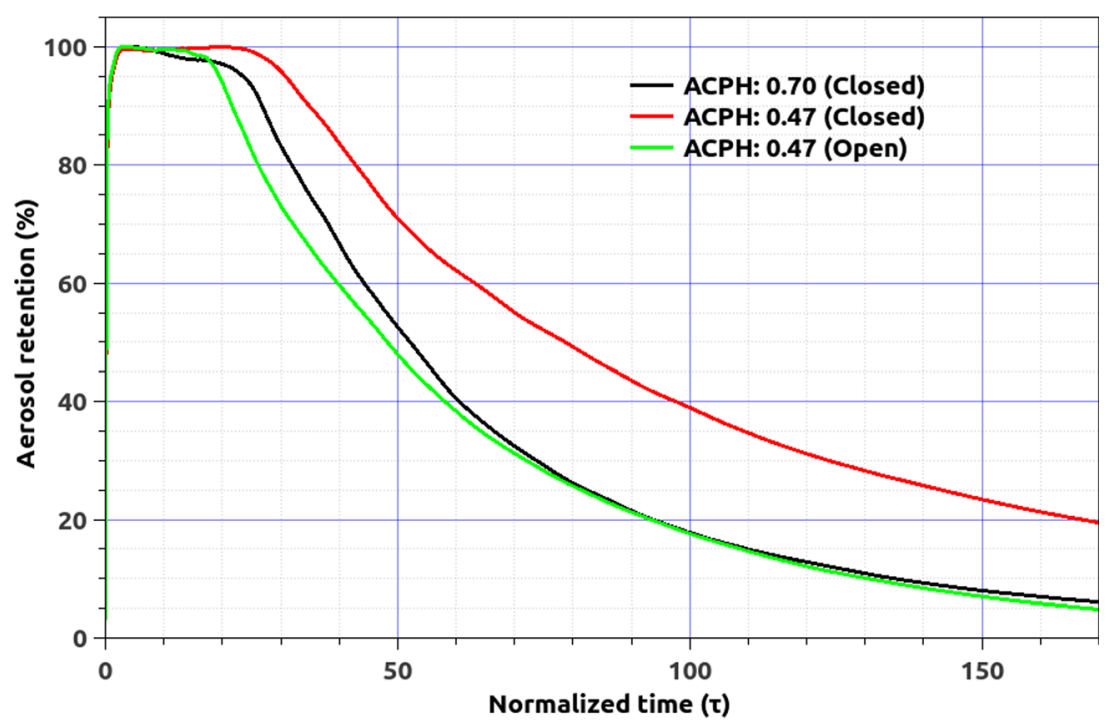

difference. The fast variation is most probably due to the breathing of the passengers, while the short variation is due to the pressure difference between the wagon and ambiance.

\section{Streamline visualization}

Considering the streamlines starting from the patient, shown in Fig. 16, they usually affect the one sitting in front of him and the one beside him. Those who sit aligned with the patient and beside the suction window have the least probability of infection. It rarely propagates in the sides, but in some cases, the streamlines may reach the furthest person, but the aerosol content tends to zero, as shown below, where the streamlines

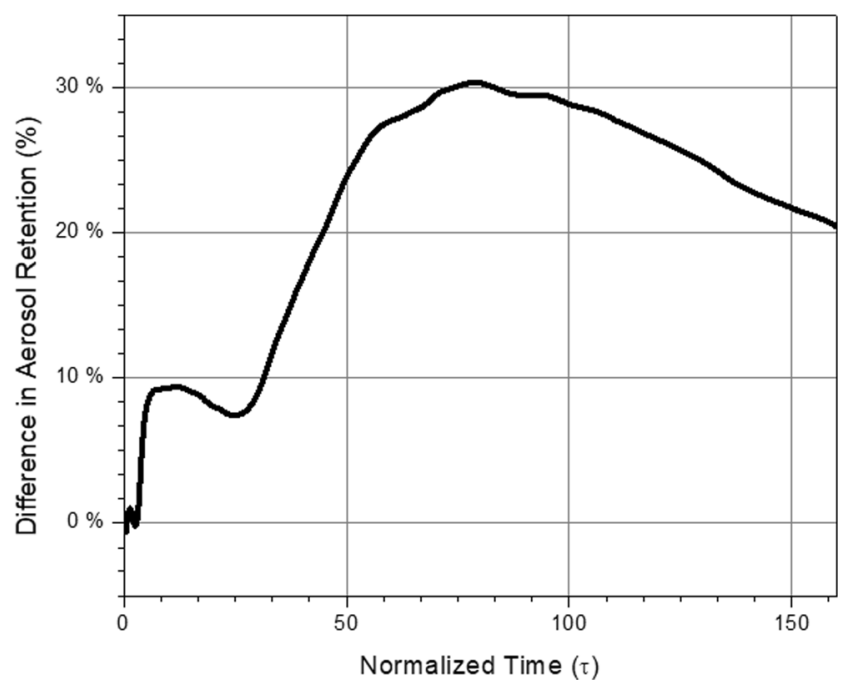

Fig. 15 Difference in aerosol retention between the windows-open ad windows-closed cases reach all people. As a conclusion, it is better to stay near windows and the ventilation windows.

\section{Summary and conclusions}

The effect of ventilation systems on the spread of airborne diseases like COVID-19 is numerically investigated using Eulerian-Lagrangian approach considering turbulence and thermal effects. The infection particles are modeled as being aerosol particles. From the simulation results, the following conclusions are clear:

1. Opening the windows helps in changing the air inside the wagon. Quantitatively speaking, opening windows reduced the time required to reach $50 \%$ WVR by $40 \%$, for the same ACPH.

2. By increasing the ventilation inlet flow rate, the infection spreading decreases considerably. In the current simulation, increasing the $\mathrm{ACPH}$ from 0.47 to 0.7 reduced the WVR from $19 \%$ to $6 \%$ after 10 minutes.

3. As the HVAC inlet flow rate increases beyond a certain value, the infection hazard does not show much difference. Changing the ACPH value from 0.7 to 0.94 reduced the WVR from $6 \%$ to $2 \%$ after 10 minutes.

4. The position of the infected person relative to the ventilation windows has a major role in the infection spreading. The closer the infected person to the suction ventilation window is, the faster the cough generated aerosols leave the wagon. In the best-case scenario, after 10 minutes from the cough, the WVR values are $19 \%$ and $35 \%$ for 
Fig. 16 Streamlines from the patient reaching the neighboring people
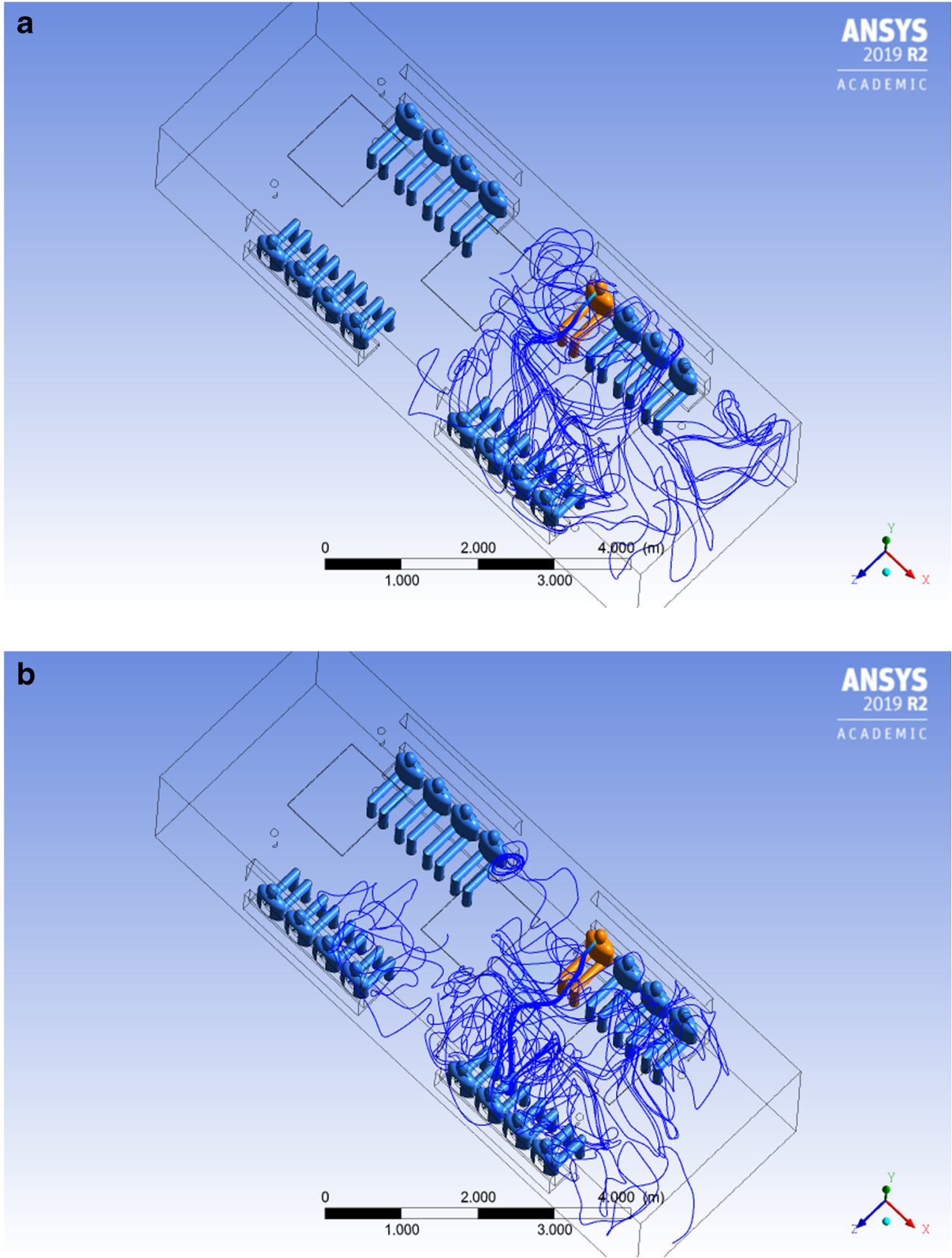

the cases where the patient is close to the ventilation suction and inlet windows, respectively.

5. Finally, this work recommends keeping the windows open and increase the volume flow rate above the average.

Author contribution Mostafa El-Salamony is responsible for the data collection, geometry and meshing, numerical setup and solution, results analysis and presentation, and first draft writing. Ahmed Moharam suggested ideas and involved in the data collection, geometry and meshing, result analysis and presentation, and first draft writing. Amr Guaily did the idea conceptualization, computational setup and supervision, result analysis and presentation, and first draft writing. Mohammed A. Boraey participated in the idea conceptualization, results analysis and presentation, Computational setup and supervision, and first draft writing.

Data availability Not applicable.

\section{Declarations}

Ethics approval and consent to participate Not applicable.

\section{Consent for publication Not applicable.}

Competing interests

The authors declare no competing interests. 


\section{References}

Abbasi F, Samaei MR (2019) The effect of temperature on airborne filamentous fungi in the indoor and outdoor space of a hospital. Environ Sci Pollut Res 26:16868-16876

Ahmed AW, Mahrous M, El Monem NA (2020) Sustainable and green transportation for better quality of life case study greater CairoEgypt. HBRC J 16(1):17-37

Andrade A, Dominski FH, Pereira ML, de Liz CM, Buonanno G (2018) Infection risk in gyms during physical exercise. Environ Sci Pollut Res 25:19675-19686

Awad AHA (2002) Environmental study in subway metro stations in Cairo, Egypt. J Occup Health 44(2):112-118

Chun C, Lin C-H, Zheng J, Chen Q (2014) Simplified models for exhaled airflow from a cough with the mouth covered. Indoor Air 24(6): $580-591$

Correia G, Rodrigues L, Silva MG, Calves TG (2020) Airborne route and bad use of ventilation systems as non-negligible factors in SARSCoV-2 transmission. Med Hypotheses 141:109781

Couaillier V (2000) Turbulent compressible flow computations. In: Peyret R, Krause E (eds) Advanced Turbulent Flow Computations. International Centre for Mechanical Sciences (Courses and Lectures), vol 395. Springer, Vienna

Dbouka T, Drikakis D (2020) On coughing and airborne droplet transmission to humans. Phys Fluids 32:053310

Eldeeb MM, Qotb AS, Riad HS, Ashour AM (2018) Optimal operation interaction (passenger/train/platform) for GreaterCairo Underground metro (GCUM) 1st and 2nd line. Ain Shams Eng J 9(4):3067-3076

Eldeeb MM, Kotb AS, Riad HS, Ashour AA (2019) Passenger Capacity of Underground Metro by the Use of Neural Net-work Program (NNP). Int J Innov Technol Explor Eng 8(10):2469-2473

Feng Y, Marchal T, Sperry T, Yi H (2020) Influence of wind and relative humidity on the social distancing effectiveness to prevent COVID19 airborne transmission: a numerical study. J Aerosol Sci 147: 105585

Ghanizadeh F, Godini H (2018) A review of the chemical and biological pollutants in indoor air in hospitals and assessing their effects on the health of patients, staff and visitors. Rev Environ Health 33(3):231245

Guo L, Hu Y, Hu Q, Lin J, Li C, Chen J, Li L, Hongbo F Characteristics and chemical compositions of particulate matter collected at the selected metro stations of Shanghai, China. Sci Total Environ 496(2014):443-452

Gupta JK, Lin C-H, Chen Q (2009) Flow dynamics and characterization of a cough. Indoor Air 19(6):517-525

Gupta JK, Lin C-H, Chen Q (2011) Transport of expiratory droplets in an aircraft cabin. Indoor Air 21(1):3-11
Hijazi J, Howieson S (2018) Displacing air conditioning in Kingdom of Saudi Arabia: an evaluation of 'fabric first design integrated with hybrid night radiant and ground pipe cooling systems. Build Serv Eng Res Technol 39(4):377-390

Khare P, Wang S, Yang V (2015) Modeling of finite-size droplets and particles in multiphase flows. Chin J Aeronaut 28(4):974-982

Kim MJ, Sankara Rao B, Kang OY, Kim JT, Yoo CK (2012) Monitoring and prediction of indoor air quality (IAQ) in sub-way or metro systems using season dependent models. Energy Build 46:48-55

Kohanski MA, Lo LJ, Waring MS (2020) Review of indoor aerosol generation, transport, and control in the context of COVID-19. In International forum of allergy \& rhinology 10(10):1173-1179

Krarti M, Ihm P (2016) Evaluation of net-zero energy-residential buildings in the MENA region. Sustain Cities Soc 22:116-125

Kwon S-B, Jeong W, Park D, Kim K-T, Cho KH (2015) A multivariate study for characterizing particulate matter (PM10, PM2. 5, and PM1) in Seoul metropolitan subway stations, Korea. J Hazard Mater 297:295-303

Marcone V (2020) Reduction of contagion risks by SARS-Cov-2 (COVID-19) in air-conditioned work environments. Pain Phys 23(4S):S475-S482

Martins V, Moreno T, Minguillon MC, Amato F, de Miguel E, Capdevila M, Querol X (2015) Exposure toairborne particulate matter in the subway system. Sci Total Environ 511:711-722

Morawska L, Tang JW, Bahnfleth W, MBluyssen P, Boerstra A, Buonanno G, Cao J, Dancer S, Floto A, Franchimon F et al How can airborne trans-mission of COVID-19 indoors be minimised? Environ Int 142(2020):105832

Pendar M-R, Páscoa JC (2020) Numerical modeling of the distribution of virus carrying saliva droplets during sneeze and cough. Phys Fluids 32(8):083305

Qiao T, Xiu G, Zheng Y, Yang J, Wang L (2015) Characterization of PM and microclimate in a Shanghai subway tunnel, China. Procedia Eng 102:1226-1232

Wen Y, Leng J, Shen X, Han G, Sun L, Yu F (2020) Environmental and health effects of ventilation in subway stations: a literature review. Int J Environ Res Public Health 17(3):1084

Yan C, Zheng M, Yang Q, Zhang Q, Qiu X, Zhang Y, Huaiyu F, Li X, Zhu T, Zhu Y (2015) Commuter exposure to particulate matter and particle-bound PAHs in three transportation modes in Beijing, China. EnvironmentalPollution 204:199-206

Zhu S, Kato S, Yang J-H (2006) Study on trans-port characteristics of saliva droplets produced by coughing in a calm in-door environment. Build Environ 41(12):1691-1702

Publisher's note Springer Nature remains neutral with regard to jurisdictional claims in published maps and institutional affiliations. 